\title{
Некоторые проблемы информатизации процессов защиты персональных данных и пути их решения
}

\author{
Аловсат Алиев \\ Институт Информационных Технологий НАНА, Баку, Азербайджан \\ alovsat_qaraca@mail.ru
}

\begin{abstract}
Аннотация - В статье анализируются некоторые социальноэкономические и правовые проблемы информатизации в сфере защиты персональных данных в условиях формирования информационного общества и электронного управления. Обосновывается актуальность указанной проблемы. Описываются сущности и особенности правовой информатизации. Раскрываются особенности информационного законодательства и право. Описываются необходимость защиты персональных данных в современном бизнесе. Анализируются проблемы создания интеллектуальных правовых систем в области защиты персональных данных. Указываются пути формирование единого информационного пространства защиты персональных данных. Рекомендованы предложения и пути решения по защите персональных данных.
\end{abstract}

Ключевые слова - правовые проблемы, информатизация правовых процессов, зацита персональных данных, правовые информационные системы, интеллектуальные юридические системы, информационное право, коммерческие информации

\section{I. ВВЕДЕНИЕ}

За последние годы в области осуществления Стратегии по информационного общества [1] и Стратегические дорожные карты [2] в Азербайджане была обеспечена стремительная интеграция страны в общемировое электронное пространство, получены значительные результаты в направлении создания электронного правительства, формирования экономики знаний, информационной безопасности и прочее. Создание космической индустрии, способствующей продвижению науки и техники, развитию отдельных направлений инновационной деятельности, обогащение интернет ресурсов, повсеместное использование социальных сетей являются наглядными показателями развития Информационно-Коммуникационные Технологии (ИКТ) в республике.

В этих условиях считается, что обеспечение беспрерывного экономического роста каждой развитой и развивающейся страны в первую очередь, требует, развития науки, инновации, техники и технологии. Человеческий капитал составляет основную часть указанного национального богатства. В этих условиях необходимо построение новой национальной инновационной инфраструктуры и системы, которые составляют основу будущего экономического развития страны [3]. В этом процессе возрос интерес к проблемам информатизации в сфере защиты персональных данных (3ПД). Это связано с тем, что современная система по защите персональных данных претерпевает изменения, связанные с реформами в различных сферах жизни [2]. Поэтому анализ и исследование самых различных проблем, связанных с формированием и применением системы ЗПД как основы национальной информационной инновационной системы страны и разработка соответствующих рекомендаций в этом направлении считаются одними из актуальных задач.

\section{II. СУЩНОСТЬ И ОСОБЕННОСТИ ПРОБЛЕМЫ ПРАВОВОЙ ИНФОРМАТИЗАЦИИ}

Под правовой информатизацией в сфере ЗПД понимается процесс создания условий полного удовлетворения информационно-правовых потребностей государственных и общественных структур, предприятий, организаций, учреждений и граждан с соблюдением защиты персональных данных на основе эффективной организации и использования информационных ресурсов c применением прогрессивных информационных технологий. Задача правовой информатизации в этой сфере определяется как формирование единого информационно-правового пространства, обеспечивающего правовую информированность всех структур общества и каждого гражданина в отдельности с учетом неприкосновенности персональных данных $[4,5]$.

Область правовой информатизации в сфере защиты персональных данных требует особого государственного внимания. Для ее развития важно применение рыночных механизмов. Становление правового порядка в государстве и обществе требует закрепления юридическими нормами таких механизмов управления, которые обеспечивают устойчивость их развития при соблюдении баланса интересов государства, общества, семьи, человека. Для создания адекватного механизма поддержки системы права служит правовая 


\section{"Informasiya təhlükasizliyinin aktual multidissiplinar elmi-praktiki problemlori” $V$ respublika konfransi, 29 noyabr 2019-cu il}

информатизация. Правовые базы персональных данных по своей сути являются распределенными. В их создании и сопровождении заинтересованы все члены общества.

При таких условиях правовая информатизация в сфере защиты персональных данных должна рассматриваться как регулируемый государством процесс взаимоувязанная создаваемых в городах и регионах, министерствах и ведомствах, учреждениях и организациях соответствующих персональных информационных систем [6]. Процесс, который активно реализуется усилиями множества независимых разработчиков, можно упорядочить только введением соответствующих стандартов и нормативов.

Можно предположить, что с дальнейшим вхождением в информационную эру определение ценности человека или иного субъекта будет иметь некое информационное выражение. Человек может быть оценен характеристиками: внешнего вида, поведения, рейтинга. Значимость ученого - количеством ссылок на его труды и выступлений на симпозиумах. Современные информационные технологии позволяют накапливать опыт и проводить сравнительные оценки подобных характеристик для каждого.

\section{III. ОСОБЕННОСТИ ИНФОРМАЦИОННОГО ЗАКОНОДАТЕЛЬСТВА И ПРАВА}

В мире постоянно идет юридическая работа по расширению информационного законодательства. Сегодня это самая быстро развивающаяся область права. Постоянно разрабатываются и уточняются законы, организуются и проводятся разные конференции. Результат этой работы представляет собой перераспределение человеческих информационных прав и свобод. Большинство государств, крупнейшие корпорации информационной индустрии отстаивают свои права в этом сложном процессе. Государственный интерес состоит в том, чтобы информация как можно скорее становилась обще доступной, чтобы препятствия и ограничения на распространение информации были минимальными. При этом должны соблюдаться свободу личности, и должно быть защищено его персональных данных [7].

Отдельные разделы информационного права развиваются уже несколько веков. Истинная его Значимость в полной мере проявилась лишь в XX веке, когда возникли мощные технические средства обработки и распространения информации, а участие людей в информационных процессах стало действительно массовым. Термин “информационное право” нельзя пока считать устоявшимся и общепринятым. Он охватывает вообще всю сферу права. Основные направления информационного права можно разделить на экономические и политические.
IV. ПРОБЛЕМЫ ЗАЩИТЫ ПЕРСОНАЛЬНЫХ ДАННЫХ В СОВРЕМЕННОМ БИЗНЕСЕ

Сейчас во всех сферах экономики и бизнеса резко выросла значимость безопасность информационного обеспечения. Грамотно построенный современный бизнес - это, по сути, информационное производство. Внутренний документооборот и технологии принятия решений, реклама и маркетинг, патенты и ноу-хау, авторские и смежные права, сбор данных о конкурентах и партнерах, обучение персонала и реинжиниринг бизнеспроцессов - все эти направления информационной деятельности по большей части являются составляющими современного бизнеса. Именно на этих направлениях возникают противоречия и конфликты, в результате которых рождается персональные право отдельного гражданине.

Высшим действующим юридическим документом, в котором закреплены информационные права граждан, является Европейская конвенции о правах человека. Согласно Всеобщей декларации прав человека, признается свобода, искать, получать и распространять информацию и идею любыми средствами и независимо от государственных границ по при этом не трогать интересы других [8].

В Азербайджане после принятия закона об информации и информатизации [9] ведется работа по формированию правовой базы для осуществления электронного документооборота [10]. Были принят законы"Об электронной цифровой подписи" (ЭЦП). Закон предполагает полностью либерализованный подход к ЭЦП. Он включает положение, основанное на принципах технологической нейтральности и адаптированности под развитие новых технологий.

Электронная цифровая подпись как реквизит электронного документа, в сфере бизнесе защищает данного электронного документа от подделки, полученный в результате криптографического преобразования информации, с использованием закрытого ключа электронной цифровой подписи. Она позволяет идентифицировать владельца сертификата ключа подписи и установить отсутствие искажения информации в электронном документе. Закрытый ключ электронной цифровой подписи - уникальная последовательность символов, известная только владельцу сертификата ключа подписи и предназначенная для создания в электронных документах электронной цифровой подписи [10].

Фактически электронную подпись можно вставить в любой электронный документ в современном бизнесе. После этого этот документ получит юридическую силу. Это аналог печати и обычной подписи на листке бумаги. В итоге получится, что не отходя от компьютера, можно заключать сделки, руководить целой конторой и др.

В настоящее время сформированы некоторые подходы к требованиям, предъявляемым к электронной подписи. 


\section{“Informasiya tohlükosizliyinin aktual multidissiplinar elmi-praktiki problemlori” \\ V respublika konfransı, 29 noyabr 2019-cu il}

Первый основан на признании в отношении электронной подписи тех же требований, что и в отношении обычной. Второй предполагает, что подпись должна быть связана с передаваемыми данными таким образом, что если они изменяются, то подпись становится недействительной. Третий подход предусматривает использование в ЭЦП криптографической технологии открытого ключа.

Следует отметить что в законе "Об электронной торговли" [11] учитывается также директивы Европарламента, ЮНДПИ, Конгресса США, а также других национальных законов, включая и Российский. Этот закон полностью сохраняет принцип либерального подхода госрегулирования электронной коммерции с признанием важной роли саморегулирования в этой сфере. Кроме этих законов были приняты также - “Об электронном документе” [10] нормативы и процедуры по применения "Asan İmza" и т.д.

Принятие таких пакетов нормативно-правовых документов частично относящихся также к защите персональных данных в современном бизнесе повлияет на развитие экономики в Азербайджане. Узаконивание электронной подписи в коммерции скорее всего сделает актуальным к усилит процесса ведения бизнеса с использованием современных новейших информационных технологий.

\section{V. ПРОБЛЕМЫ СОЗДАНИЯ ИНТЕЛЛЕКТУАЛЬНЫХ ПРАВОВЫХ СИСТЕМ В ОБЛАСТИ ЗАЩИТЫ ПЕРСОНАЛЬНЫХ ДАННЫХ}

Обоснование любых юридических документов в области защиты персональных данных осуществляется ссылкой на статьи нормативно-правовых актов, регулирующих соответствующие правоотношения. При этом недостаточно знать, как решать юридическую задачу, необходимо также обосновать решение. Следовательно, нужны сведения о действии нормативноправовых актов, о внесенных в них изменениях.

Отсутствие информационных и интеллектуальных систем правовой информации в сфере защиты персональных данных в государственных органах приводит иногда к принятию ими не эффективных законных решений, ущемляющих права граждан. Отсутствие современной технологий приводит к нарушениям процессуальных сроков рассмотрения дел. В результате этого увеличиваются срок содержания обвиняемых под стражей, увеличивается издержки сторон в гражданском процессе. Кроме того, граждане, не являющиеся профессиональными юристами, испытывают значительные затруднения при самостоятельном поиске информации о правовом регулировании в конкретной ситуации и применении права.

Поэтому вопросы применения автоматизированных систем правовой информации по защиты персональных данных в правоохранительной и юридической деятельности являются в настоящее время весьма актуальными. Системы правовой информации можно определить как информационные компьютерные системы, обеспечивающие доступ к правовой информации, т.е. сведениям о фактах, событиях, предметах, лицах, явлениях, протекающих в правовой сфере жизни общества, содержащихся как в нормах права, так и других источниках и используемых государством и обществом для решения задач правотворчества и реализации права.

Существующие в настоящее время системы правовой информации можно разделить на информационноправовые системы и интеллектуальные юридические консультационные системы [12]. Информационноправовые системы в области ЗПД в зависимости от характера содержащейся в них правовой информации подразделяют на документальные и фактографические системы. Документальные информационно-правовые системы содержат тексты документов: нормативноправовых актов, актов применения права, других документов, принятых государственными органами. Фактографические информационно-правовые системы содержат ненормативную правовую информацию: данные криминалистического учета, статистические и социологические данные, необходимые для решения юридических задач.

Интеллектуальные юридические консультационные системы осуществляют моделирование рассуждений юристов при решении задач профессиональной деятельности. Результатом работы таких систем является решение юридической задачи с еe обоснованием: информация о правовом статусе (правах и обязанностях) субъектов правоотношения, рекомендуемая линия поведения, соответствующая нормам права и направленная на удовлетворение интересов пользователя системы.

Интеллектуальные юридические консультационные системы, решающие задачи на уровне экспертов в определенной области юридической деятельности, называются экспертными юридическими компьютерными системами [13]. Они используются в тех случаях, когда необходимо решить юридическую задачу человеку, не имеющему необходимой юридической подготовки, либо юристу, встречающемуся с задачей, выходящей за пределы его профессиональной компетентности. Помимо рассмотренной выше функции экспертные юридические системы применяются для обучения студентов юридических учебных заведений и для повышения квалификации юридических кадров [14]. В государственных правоохранительных органах обычно существует система ведомственных распределенных и локальных информационно-правовых систем. Такие системы обычно бывают государственными или негосударственными. 


\section{“Informasiya tohlükosizliyinin aktual multidissiplinar elmi-praktiki problemlori” \\ V respublika konfransı, 29 noyabr 2019-cu il}

\section{VI. ФОРМИРОВАНИЕ ЕДИННОГО ИНФОРМАЦИОННОГО ПРОСТРАНСТВА ЗАЩИТЫ ПЕРСОНАЛЬНЫХ ДАННЫХ}

Сложившаяся обстановка диктует необходимость информационного обеспечения правоохранительных органов и юридических процессов по защиты персональных данных. Улучшение состояния борьбы с различными видами преступности в этой сфере можно решить только путем создания единого информационного пространства (ЕИП) правоохранительных органов по ЗПД [15].

ЕИП по ЗПД представляет собой совокупность баз и банков данных, технологий их ведения и использования, информационно-телекоммуникационных систем и сетей, функционирующих на основе единых принципов и по общим правилам, обеспечивающим информационное взаимодействие правоохранительных органов республики.

Формирование и развитие ЕИП правоохранительных органов сфере ЗПД предусматривает, обеспечения оперативного доступа к имеющимся информационным ресурсам и проведение работ по их включению в единое информационное пространство. Действующие и разрабатываемые в настоящее время ведомственные и межведомственные распределенные системы сбора, обработки и накопления информации могут служить базой внедрения новых информационных технологий. Формирование информационных ресурсов - одна из ключевых проблем создания ЕИП правоохранительных органов, которые включают информацию и знания, а также средства для обеспечения доступа к информации.

Совершенствование информационной инфраструктуры правоохранительных органов в сфере защиты персональных данных должно учитывать различный уровень информатизации в разных органах. При этом необходимо определить оптимальные средства связи и передачи данных для каждого органа [16]. Для обеспечения информационного взаимодействия правоохранительных органов должна быть предусмотрена разработка соответствующих нормативно-правовых актов.

\section{VII. ВЫВОДЫ И ПРЕДЛОЖЕНИЯ}

Международный опыт подтверждает актуальность проблем информационной безопасности в деле обеспечения ЗПД. Информационное взаимодействие правоохранительных органов наряду с правовым обеспечением требует принятия организационных и технических мер по защите информации: предотвращение утечки, утраты, подделки информации; предотвращение несанкционированного доступа и действий по уничтожению, модификации, искажению, копированию, блокированию информации; предотвращение других форм незаконного вмешательства в информационные ресурсы и информационные системы. Для информационного обеспечения правоохранительных органов в сфере защиты персональных данных предлагается создание Единой информачионной сети, которая должна состоять из следующих подсистем: 1) единой (взаимоувязанной) телекоммуникационной сети связи; 2) единой системы информационного обмена по защиты персональных данных; 3) систем хранения и обработки персональных данных; 4) систем защиты информации. Такие системы должны иметь повышенную надежность и строиться на базе резервируемых спутниковых и высокоскоростных наземных каналов связи. Система должна также предоставлять современные виды сетевого сервиса, включая доступ к удаленным локальным сетям, цифровую передачу речи, аудио и видеоконференции, подключение систем охранной и прочей сигнализации и видеонаблюдения и пр.

Система позволит поднять на качественно новый уровень борьбу с преступностью и создает для руководства оперативную и надежную систему передачи информации по защиты персональных данных. Обеспечивает непосредственный доступ к автоматизированным банкам данных, системам оперативного и оперативно-справочного учета информационных центров в области ЗПД. Объединит телекоммуникационные системы различного уровня в единую сеть на основе стандартных сетевых протоколов, типовых программных средств, коммуникационного оборудования и способов сопряжения. Осуществление выше указанных мероприятий повысит уровня защиты персональных данных и обеспечит безопасности граждан и организаций.

\section{ЛИТЕРАТУРА}

[1] Azərbaycan Respublikasında informasiya cəmiyyətinin inkișafına dair 2014-2020-ci illər üçün Milli Strategiya. Bak1, 2 aprel 2014-cü il. https://president.az/articles/11312

[2] Milli iqtisadiyyat və iqtisadiyyatın əsas sektorları üzrə Strateji Yol Xəritələri. Bakı, 6 dekabr 2016-c1 il, https://president.az/articles/21953

[3] А.Г.Алиев. Проблемы информатизации общества и экономики // Баку, “ЭЛМ”, 2003, 460 с.

[4] А.Г.Алиев. Теоретико-прикладные аспекты информатизации гуманитарных отраслей // Баку, “ЭЛМ”, 2006 г., 474 с.

[5] Д.А.Ловцов, А.В.Федичев. Место и роль правовой информатики в системе информационно-правовых знаний. // Правовая информатика, 2017, №1, стр.5-12.

[6] «Fərdi məlumatlar haqqında Azərbaycan Respublikasının Qanunu». № 998-IIIQ. Bakı ş̧һri, 11 may 2010-cu il, http://www.eqanun.az/framework/19675

[7] İnformasiya əldə etmək haqqında Azərbaycan Respublikasının Qanunu Bak1 şəhəri, 30 sentyabr 2005-ci il. № 1024-IIQ. http://www.eqanun.az/framework/11142

[8] Европейская конвенция по правам человек. https://www.echr.coe.int/Documents/Convention_RUS.pdf

[9] İnformasiya, informasiyalașdırma və informasiyanın mühafizəsi haqqında Azərbaycan Respublikasının Qanunu. Bakı şəhəri, 3 aprel 1998-ci il. № 460-IQ. http://e-qanun.gov.az/framework/3525

[10] Elektron imza və elektron sənəd haqqında Azərbaycan Respublikasının Qanunu. Bakı şəhəri, 9 mart 2004-cü il. № 602-IIQ. http://www.eqanun.az/framework/5916

[11] Elektron ticarət haqqında Azərbaycan Respublikasının Qanunu. Bak şəhəri, 10 may 2005-ci il. № 908-IIQ. http://www.eqanun.az/alpidata/framework/data/10/f_10406.htm 
[12]A.Musca. legal informatics as fundamental instrument utilized in law administration. International Conference on Uniformization of the Law Legal Effects and Social, Political, Administrative Implications, Romania, oct. 23-25, 2014, pp.517-524.

[13]A.С.Лагоха. Некоторые особенности использования юридических экспертных систем. Вестник Алтайской академии экономики и права. 2013. №S3(32), стр.86-88.

[14] Li Song. Research of key technical issues based on computer forensic legal expert system. International Symposium on Computers and Informatics (ISCI), China, jan 17-18, 2015. Book Series: ACSR-Advances in Comptuer Science Research, vol.13. pp.14311437.

[15] А.В.Долматов, Е.А. Долматов. Особенности и проблемы правового регулирования защиты персональных данных. Вестник СанктПетербургской юридической академии. 2018, №3(40), стр.53-60.

[16] Greenleaf Graham, Mowbray Andrew, Chung Philip. Building и Sustainable free legal advisory systems: Experiences from the history of AI \& law. Computer law \& security review, 2018, vol. 34, issue 2, pp.314-326

\section{SOME PROBLEMS OF INFORMATIZATION OF PERSONAL DATA PROTECTION PROCESSES AND WAYS OF THEIR SOLUTION}

Alovsat Aliyev

Institute of Information Technology of ANAS, Baku, Azerbaijan alovsat_qaraca@mail.ru

Abstract - The article analyzes some socio-economic and legal problems of informatization in the field of personal data protection in the context of the formation of the information society and electronic governance. The relevance of this problem is substantiated. The essence and features of legal informatization are described. The features of information legislation and law are revealed. The necessity of protecting personal data in modern business is described. The problems of creating intelligent legal systems in the field of personal data protection are analyzed. The ways of forming a single information space for protecting personal data are indicated. Suggestions and solutions for protecting personal data are recommended.

Keywords - legal problems, informatization of legal processes, personal data protection, legal information systems, intellectual legal systems, information law, commercial information 